\title{
De balas, política y medios informativos: análisis de la cobertura periodística de tiroteos escolares en The New York Times$$
\text { (1999-2018)* }
$$

[Artículos]

\author{
Eduar Barbosa Caro** \\ Camila Granados Pérez ${ }^{* * *}$
}

Recibido: 25/11/202O

Aprobado: 5/12/2020

Citar como:

Barbosa, E. y Granados, C. (2021). De balas, política y medios informativos: análisis de la cobertura periodística de tiroteos escolares en The New York Times (1999-2018). Análisis, 53(98). https://doi.org/10.15332/21459169.6312

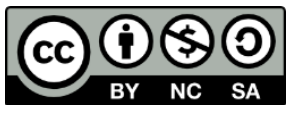

\section{Resumen}

Este trabajo presenta los resultados de un análisis a la cobertura realizada por el diario The New York Times a los tiroteos escolares de Columbine (1999), Virginia Tech (2007), Sandy Hook (2012) y Marjory Stoneman (2018), considerados los más letales de Estados Unidos en los

\footnotetext{
* Artículo de investigación derivado de trabajo de grado en Periodismo y Opinión Pública (Universidad del Rosario).

** Magíster en Comunicación. Universidad del Rosario, Colombia. Correo electrónico: eduar.barbosa@urosario.edu.co; ORCID: https://orcid.org/0000-0003-0297-8224 *** Profesional en Periodismo y Opinión Pública. Universidad del Rosario, Colombia. Correo electrónico: camila.granados@urosario.edu.co; ORCID: https://orcid.org/00000003-4424-0404
} 
últimos 25 años. A través de un análisis de contenido basado en la teoría del encuadre, el estudio revela que, tras el tiroteo de Sandy Hook, se presentó un cambio narrativo que se acentuó con el suceso de Marjory Stoneman, en el cual el debate político se convirtió en el protagonista, más allá del suceso mismo. Esto, a su vez, influyó en el ciclo de vida de las noticias. Un análisis del entorno sociopolítico que rodeó a cada uno de estos sucesos permitió concluir que, al tiempo que este debate se masificó, los actores políticos relacionados con los hechos adquirieron mayor relevancia, un síntoma de la sociedad cambiante dentro de la cual se desarrollan los eventos. De esta forma, el diario tomó un rol más crítico respecto a su gestión y dio más importancia al marco de conflicto sobre el marco de interés humano. Esta relación entre producción noticiosa, sucesos trágicos y política permite discutir cómo la voz y el poder de un medio, al reconocer su propio potencial transformador, puede determinar aspectos básicos de la cobertura, como la caracterización de los actores involucrados o los temas en los cuales se hace énfasis en los artículos.

Palabras clave: tiroteos masivos, debate de armas, mediatización de la violencia, cobertura mediática, encuadres.

\section{Bullets, politics, and news media: analysis of journalistic coverage of school shootings in The New York Times's (1999-2018)}

\section{Abstract}

This article presents the results of an analysis of the coverage by The New York Times to the Columbine (1999), Virginia Tech (2007), Sandy Hook (2012) and Marjory Stoneman (2018) school shootings, considered as the deadliest school shootings in the United States in the last 25 years. Through a content analysis based on the framing theory, the study reveals that, after the Sandy Hook shooting there was a narrative shift that was accentuated with the Marjory Stoneman event, in which the political debate played a leading part, beyond the event itself. This in 
turn, influenced the life cycle of the news. An analysis of the sociopolitical context surrounding each of these events allowed us to conclude that, as this debate became more widespread, the political actors related to these events acquired greater relevance, a symptom of the changing society in which the events unfolded. In this way, the newspaper took a more critical role regarding its management and gave more importance to the conflict frame over the human interest frame. This relationship between news production, tragic events and politics allows us to discuss how the voice and power of a media, by recognizing its own transformative potential, can determine basic aspects of the coverage, such as the characterization of the actors involved or the topics that are emphasized in the articles.

Keywords: mass shooting; gun control; mediatization of violence; media coverage; framing.

\section{Balas, política e mídia: análise da cobertura jornalística de tiroteios em escolas no The New York Times (1999-2018)}

\section{Resumo}

Este artigo apresenta os resultados de uma análise da cobertura do The New York Times sobre os tiroteios escolares de Columbine (1999), Virginia Tech (2007), Sandy Hook (2012) e Marjory Stoneman (2018), considerados os mais letais dos Estados Unidos nos últimos 25 anos. Por meio de uma análise de conteúdo baseada na teoria do enquadramento, o estudo revela que, após o tiroteio de Sandy Hook, foi apresentada uma mudança narrativa que foi acentuada com o ocorrido de Marjory Stoneman, no qual o debate político se tornou o protagonista, mais além do próprio ocorrido. Isso, por sua vez, influenciou o ciclo de vida das notícias. Uma análise do ambiente sociopolítico que cercava cada um desses eventos nos permitiu concluir que, à medida que esse debate se tornava mais concorrido, os atores políticos relacionados aos acontecimentos se tornaram mais relevantes, sintoma da mudança da 
sociedade em que ocorrem os eventos. Dessa forma, o jornal assumiu um papel mais crítico em relação à sua gestão e deu mais importância ao quadro de conflitos sobre o quadro de interesse humano. Essa relação entre produção de notícias, eventos trágicos e política nos permite discutir como a voz e o poder de um meio, reconhecendo seu próprio potencial transformador, podem determinar aspectos básicos da cobertura, como a caracterização dos atores envolvidos ou os temas sobre os quais os artigos são enfatizados.

Palavras-chave: tiroteos em massa, debate sobre armas, mediatização da violência, cobertura da mídia,enquadramento.

\section{Introducción}

La presente investigación se enfoca en analizar la cobertura de los cuatro tiroteos escolares más letales de los últimos 25 años en Estados Unidos a través de las publicaciones del diario The New York Times. Este análisis vincula el debate por el control de armas, las principales posturas dominantes en este y el contexto sociopolítico del país durante el periodo, para identificar posibles influencias que pudieron impulsar un cambio dentro de la cobertura noticiosa de estos eventos.

Análisis previos de este tipo se enfocan en un hecho en concreto (Altheide, 2009) o dan un panorama general respecto a la relación de los medios con estos incidentes (Duwe, 2000). Aunque existen estudios longitudinales (Silva y Capellan, 2018) y comparativos (Schildkraut y Muschert, 2014) más recientes, ninguno se enfoca en el panorama político dentro del cual se produjeron los hechos y sus noticias, y su posible incidencia en la cobertura. Esta es una línea a la que se intentó aportar desde el presente trabajo.

Así, este estudio tiene la intención de contribuir a la transformación social, al buscar comprender la cobertura mediática enmarcada en un contexto político y social cambiante, síntoma de otras circunstancias que 
intensifican el debate tanto para una posición como para la otra. Al mismo tiempo, observamos el medio como un actor más dentro del debate, lo cual brinda nuevas luces sobre cómo abordar la cobertura mediática de hechos trágicos, y cómo esa voz y el poder que tiene el medio al reconocer su propio potencial transformador puede determinar aspectos básicos para su divulgación, como la caracterización de los actores involucrados o los temas en los cuales se hace énfasis en los artículos.

\section{El debate sobre el control de armas}

En el centro del debate por la regulación de armas en Estados Unidos se encuentra la Segunda Enmienda a la Constitución, implementada en 1791, que establece que el derecho de los individuos a portar armas no debe ser restringido ${ }^{1}$. Las distintas interpretaciones a esta cláusula han sido objeto de discusión desde que se adoptó. No obstante, este debate se intensificó hacia la segunda mitad del siglo XX, con el ascenso y la popularización de la Asociación Nacional del Rifle (NRA), fundada en 1871 y que se fortaleció a partir de la década de los setenta, tras aliarse con los sectores más conservadores durante la llamada ola del nuevo conservatismo, expandido en la década de los ochenta (Waldman, 2015). Dos posiciones imperan en el debate por la regulación de armas: el partido Demócrata aboga por un mayor control de las armas que limite el acceso de la población a estas; los republicanos defienden políticas que permitan a los ciudadanos armarse como una forma de defensa propia (Newman y Hartman, 2017).

Durante la segunda mitad del siglo XX se implementaron dos intentos legislativos para regular armas: en 1968 se introdujo el Acta por el Control de Armas, con la que se prohibió la venta para personas que hayan

\footnotetext{
${ }^{1}$ El apartado completo de la Segunda Enmienda enuncia que: "Una milicia bien regulada, es necesaria para la seguridad de un Estado libre, el derecho de las personas para tener y portar armas, no será infringido (Traducción propia)" (Waldman, 2015, p. 11).
} 
cometido un crimen y se categorizaron las armas de fuego con acceso restringido; esta propuesta surgió tras los asesinatos de John F. Kennedy, Martin Luther King Jr. y Robert Kennedy. Por otro lado, la ley Brady se implementó en 1993. Fue una enmienda al decreto de 1968 que exige la revisión de antecedentes legales de los compradores e impuso un periodo de espera de mínimo cinco días para adquirir el arma (Waldman, 2015), regulaciones que solo aplican a puntos de venta legales y con licencia. Otros esfuerzos por regular la posesión de armas se remiten a jurisdicciones federales que aplican solo dentro de un estado.

\section{Tiroteos masivos: actos de gran impacto}

Sumiala y Muschert (2012) afirman que un determinante fundamental para rastrear posibles motivos que llevan a que este tipo de incidentes sucedan es el poder del mensaje que transmiten los tiroteos: su impacto trasciende las barreras locales y nacionales, y las consecuencias no solo repercuten dentro del ámbito social, sino del político y cultural. Esto implica que, cuando sucede un tiroteo masivo, este tema se posiciona de forma casi inmediata en la agenda mediática y en la agenda política a nivel regional y nacional, lo que a su vez lleva a que ocupe un lugar central en la construcción de la opinión pública de los individuos (Birkland y Lawrence, 2009). Este impacto se puede medir en al menos tres aspectos: i) debates por el control de armas; ii) percepción de seguridad en entornos cotidianos; y iii) el impacto cultural de este tipo de sucesos.

En cuanto a la primera categoría, se puede afirmar que los tiroteos masivos tienen un fuerte impacto dentro de la introducción de políticas de regulación de armas siempre y cuando exista un ambiente político que lo posibilite (Cook y Goss, 2014). Además de los magnicidios que inspiraron la implementación del acta de regulación de 1968, la ley Brady de 1993 se propuso tras el intento de asesinato al presidente Ronald Reagan, en 1981 
(Waldman, 2015). Además, la ocurrencia de tiroteos masivos aumentó en al menos un 15 por ciento los esfuerzos por implementar políticas más efectivas ante el porte de armas (Luca et ál., 2020).

Este tipo de incidentes influyen en la percepción generalizada respecto a la seguridad. Rocque (2012) afirma que eventos como los tiroteos escolares ocurridos durante las últimas dos décadas han generado un fuerte impacto dentro de la forma en que las personas conciben su seguridad en estos espacios. Esto conduce a una sensación generalizada de "pánico moral [traducción propia]" (Rocque, 2012, p. 304), en la que los entornos se perciben como mucho menos seguros, a pesar de que solo $0,12 \%$ de las muertes por violencia armada suceden durante tiroteos escolares (Schultz et ál., 2013).

Simultáneamente, Kocsis (2015) afirma que esta sensación de inseguridad motiva a las personas a armarse, debido a que la cultura por las armas en Estados Unidos se ha construido y reproducido a partir de la idea del arma como un símbolo de poder y seguridad, una perspectiva influenciada por productos culturales. La mayoría de los planes de acción, sin embargo, se han enfocado en intentar ampliar los canales de comunicación entre directivos y estudiantes, y en crear estrategias para evitar que se ingresen armas a las escuelas, planes que han fracasado debido a la presión política ejercida por quienes apoyan el derecho a portar armas (Rocque, 2012).

De esta manera, los tiroteos masivos que ocurren dentro de los entornos escolares son actos con fuertes repercusiones en diversos ámbitos, a corto y largo plazo, pues inciden tanto en el imaginario colectivo sobre seguridad y armas como en los esfuerzos legislativos y la presión externa que se ejerce sobre el Congreso para que se concreten cambios. 


\section{La mediatización de la violencia: aproximaciones sobre el rol de los medios en los tiroteos}

Los tiroteos masivos se convierten en fenómenos mediáticos a nivel global desde el momento en que suceden, lo que genera una intensa necesidad en la audiencia por conocer sus circunstancias y consecuencias (Sumiala y Muschert, 2012). En este tipo de casos, sin embargo, el rol de los medios va más allá del mero objetivo de informar, pues estos se establecen como moldeadores de las perspectivas que adquieren los individuos sobre la realidad, un fenómeno denominado mediatización (Sumiala y Muschert, 2012). Esta hace referencia a la idea de que los procesos de comunicación se ven permeados por el mensaje transmitido por los medios (Krotz y Hepp, 2013), al penetrar las esferas de pensamiento del individuo.

El concepto de 'mediatización de la violencia' implica que las perspectivas de un individuo en torno a las temáticas asociadas al problema -seguridad, políticas e incluso dinámicas sociales- están mediadas, en parte, por la forma en la cual los medios le presentan la información. La manera en la que se transmite, los recursos a los que se acude y el lenguaje utilizado tienen la función de generar un mensaje que es interpretado por la audiencia, y que permite a los medios imponer cierto control social (Altheide, 2009). Así, los medios tienen un papel central en cómo la audiencia percibe los tiroteos masivos y cómo reacciona ante ellos (Muschert, 2007), de modo que influyen dentro del proceso de toma de decisiones respecto a ellos mismos (Sumiala y Muschert, 2012).

\section{Making and Breaking news: la relación simbiótica entre los medios y los tiroteos}

Los tiroteos masivos se perciben como una anomalía, como el caso extremo de violencia por excelencia (Duwe, 2000), no solo por su rareza sino por las circunstancias de los hechos: tienden a tener corta duración, 
generar alto nivel de pánico y una alta cifra de víctimas. Se ha demostrado que, además, las situaciones de asesinato masivo en las cuales un individuo abre fuego en espacios públicos contra víctimas aleatorias son consideradas como las más noticiosas (Duwe, 2000). Otros autores han determinado que existen víctimas que reciben mayor atención: de raza blanca, que se encuentran en rangos de edad extremos, pertenecen a clase social media o alta y son asesinados por extraños (Schildkraut et ál., 2017).

Tiroteos masivos como el de un supermercado en Tucson, Arizona, que dejó seis muertos (2011), y el de la escuela de Sandy Hook (2012) estuvieron entre los hechos noticiosos más importantes del año (Drake, 2013). $\mathrm{Al}$ atraer un alto nivel de audiencia, estos incidentes generan rentabilidad para los medios (Duwe, 2000), lo que lleva a la necesidad de seguir usando la magnitud de la noticia para generar nuevos enfoques y así aumentar su ciclo de vida (Chyi y McCombs, 2004).

Adicionalmente, los tiroteos masivos son vistos como actos con un fuerte contenido simbólico, con un número de víctimas relativamente bajo -cuya selección también responde a la idea de transmitir un mensaje (Rocque, 2012) - , pero con el potencial de alcanzar audiencias globales. Esto, a su vez, se relaciona con la necesidad por parte de los perpetradores de ganar notoriedad a través de los hechos. Los tiradores generalmente se perciben a sí mismos como personas marginalizadas (Newman y Fox, 2009) y los medios convierten a los victimarios en celebridades casi de forma inmediata cuando ocurren los hechos. De esta manera, los tiroteos make and break news (Sumiala y Muschert, 2012, p. 17), pues se convierten en hechos rentables para los medios que atraen una gran atención por parte de la audiencia. 


\section{La cobertura del tiroteo: los medios como plataformas de performance}

El rol simbólico de los tiroteos está estrechamente conectado, simultáneamente, con la necesidad de los medios de apelar a las emociones de las personas, pues se convierten en hechos trágicos y es fundamental darles una cara humana a través de la cobertura, tanto desde el rol de la víctima como del victimario (Warnick et ál., 2010). Así, la mediatización de los tiroteos también abarca la mediatización del suceso, de las consecuencias, de las reacciones, del duelo y del luto (Sumiala y Muschert, 2012), al estructurar la narrativa en torno al tiroteo como un hecho dramático. Hawdon et ál. (2012) denominan a este enfoque como el "marco trágico [traducción propia]" (p. 852), visto como una manera de presentar las noticias con el propósito de mitigar la idea de que la comunidad, las prácticas y el entorno social son culpables de que sucediesen estos incidentes. Se enfoca principalmente en el accionar del victimario y en cómo este repercutió en la comunidad misma, que se convirtió en una víctima involuntaria de los hechos.

Sumiala y Muschert (2012) afirman que los tiroteos se convierten, entonces, en escenarios para implementar elementos dramáticos que se adaptan fácilmente por la naturaleza trágica de estos, lo que a su vez atrae la atención de los medios. Así, según los autores, en la cobertura de estos sucesos se presenta una convergencia entre lo informativo y lo performativo, entre el mito y el logos. Este concepto está ligado con lo que Rocque (2012) denomina el aspecto ritual del tiroteo, visto como un acto ceremonial tanto por los perpetradores como por la audiencia. Así, un asesinato masivo se convierte en un espectáculo público (Warnick et ál., 2010). Entre más elaborado sea el modus operandi, existirá mayor necesidad por parte de los medios de profundizar en esos aspectos que hicieron distintivo a este suceso de los demás, un concepto conocido como 
la "violencia ceremonial [traducción propia]” (Warnick et ál., 2010, p. 373).

\section{De Columbine a Marjory Stoneman: los cuatro tiroteos analizados}

El tiroteo de Columbine es comúnmente considerado como el tiroteo masivo que sentó el modus operandi para sucesos posteriores. En abril de 1999, los estudiantes Eric Harris y Dylan Klebold abrieron fuego en espacios concurridos de la institución, con un saldo de 13 personas muertas y 21 heridas. Posteriormente, se suicidaron (Larkin, 2007). Este se convirtió en el hecho más seguido del año y motivó al Congreso, de mayoría republicana, a impulsar leyes de seguridad escolar, más no de regulación de armas, según Birkland y Lawrence (2009). El incidente ocurrió durante la segunda administración del demócrata Bill Clinton.

El tiroteo de Virginia Tech, ocurrido en 2007, es considerado hasta la fecha como el tiroteo escolar más letal en la historia de Estados Unidos, con un saldo de 33 víctimas. Seung-Hui Cho, un estudiante con historial de enfermedades mentales, asesinó a 32 personas en los dormitorios y las aulas de clase de la institución, envió una carta y un video a la cadena de noticias NBC y se suicidó (Schildkraut, 2012).

Después del tiroteo, en 2008, el entonces presidente saliente, el republicano George Bush, firmó un proyecto de ley con el que se fortalecía la revisión de antecedentes de las personas con problemas mentales antes de comprar un arma (Schildkraut y Hernández, 2014). Durante su administración también expiró la ley Brady de 1993, que no fue renovada por influencia de la NRA y por los temores de los demócratas de perder votos en las zonas rurales -que históricamente apoyan la posesión de armas- (Simon, 2004). 
En diciembre de 2012, Adam Lanza, un exestudiante de la escuela primaria de Sandy Hook obsesionado con el tiroteo de Columbine, asesinó a 20 estudiantes de entre seis y ocho años, y a seis funcionarios en menos de once minutos y se suicidó (Sedensky, 2013). Este evento es considerado como el "punto de quiebre [traducción propia]" (Schultz et ál., 2013, p. 65) sobre el debate respecto al control al porte de armas. El presidente de turno, el demócrata Barack Obama, se comprometió con imponer nuevas sanciones a la compra de armas, medidas que no avanzaron en el Congreso, de mayoría republicana (Reich y Barth, 2017).

El llamado a la acción que se masificó durante Sandy Hook se repitió tras el tiroteo en la escuela Marjory Stoneman Douglas, ocurrido en febrero de 2018, cuando el exestudiante Nikolas Cruz entró a la escuela, activó las alarmas de emergencia en los pasillos para hacer que los estudiantes salieran de sus salones y abrió fuego, con el que asesinó a 17 personas. Cruz fue arrestado (Fausset, 2018). Este hecho llevó a un movimiento masivo liderado por los estudiantes de la institución, que exigían un control más riguroso al porte de armas, denominado The March for Our Lives (Almasy, 25 de marzo de 2018).

Tras el tiroteo, el presidente republicano de turno, Donald Trump, anunció nuevas medidas contra el uso de armas, entre estas, prohibir la venta de un elemento que convierte las armas semiautomáticas en automáticas (Savage, 2018) y una polémica propuesta de armar a los profesores que no avanzó en el Congreso, dominado por republicanos.

\section{El encuadre y los medios}

El framing hace referencia al proceso a través del cual se crea un marco interpretativo (o frame, en inglés), para abordar una problemática desde un determinado enfoque (Birkland y Lawrence, 2009). Este hilo conductor que guiará al tema permite a la audiencia adquirir un mayor 
entendimiento, al hacer énfasis en un aspecto específico de la problemática, en lugar de abarcar el problema por completo (Muschert, 2009). Sin embargo, la aplicación de esta teoría en la práctica implica que, al elegir hacer énfasis en algunos aspectos sobre otros, los medios moldean la perspectiva del público en torno a la realidad y su interpretación (Krotz y Hepp, 2013). Esto ocurre principalmente en los temas que son considerados controversiales o que son objeto de debate (Birkland y Lawrence, 2009).

El framing posibilita la "promoción de un problema en particular, de una definición, una interpretación causal, una evaluación moral y la recomendación respecto a cómo tratar un objeto [traducción propia]" (Entman, 1992, p. 52). Tiene en cuenta el concepto de mediatización, lo que implica que el proceso de framing a través del cual se aborda una problemática influye en el ámbito cotidiano de los individuos, bien sea en su relación con el mundo, su interpretación de la realidad o su posición en los debates políticos (Krotz y Hepp, 2013).

Cuando se hace referencia al framing de un tema, es necesario evaluar la posibilidad que tiene de ser visto como relevante, es decir, durante cuánto tiempo este puede ser considerado noticioso y seguir captando la atención de la audiencia. A esto, Chyi y McCombs (2004) lo denominan el "ciclo de atención en el problema [traducción propia]” (p. 23). Dicho ciclo es variante, y depende del hecho y sus circunstancias. Así, un tiroteo escolar cuyo impacto en la opinión pública reviva el debate sobre el porte de armas y lleve a diversos esfuerzos políticos y movimientos sociales, cuyas repercusiones se extiendan por meses, tendrá un mayor ciclo de vida que, por ejemplo, un accidente que dejó múltiples víctimas.

Durante este ciclo de vida, los medios acuden a distintos marcos de interpretación para mantener la noticia fresca y adaptarla a los hechos 
inmediatos, lo cual permite presentar la información desde diversos enfoques, y logra que el público se mantenga conectado con la historia (Schildkraut y Muschert, 2014).

Diversos estudios se enfocan en analizar los modelos de framing aplicados durante el ciclo de vida de una noticia. Chyi y McCombs (2004) y Schildkraut y Muschert (2014) han analizado posibles cambios de framing en relación con variables espaciotemporales de los tiroteos de Columbine y Sandy Hook, respectivamente, y establecieron un modelo de estudio aplicable a estos sucesos. En consonancia, en su trabajo respecto al framing de los debates políticos en Europa, Semetko y Valkenburg (2000) aplican un modelo de análisis desde cinco tipos de frame: $i$ ) de atribución de responsabilidad; ii) de conflicto; iii) de interés humano; iv) de consecuencias económicas; y v) de moralidad.

Semetko y Valkenburg (2000) definen el frame de conflicto como aquellas noticias que se enfocan en la confrontación entre dos o más actores para captar una mayor audiencia. Por otro lado, la atribución de responsabilidad presenta un problema como consecuencia de las acciones de un individuo, un grupo en particular o del Estado, de forma que la noticia guía al lector a creer que dicho sujeto es responsable de la problemática. El frame de interés humano, por su parte, busca darle un rostro humano a la noticia y apelar a las emociones de la audiencia. El frame de consecuencias económicas se enfoca en el impacto económico que podría generar la problemática y, por último, el frame de moralidad hace referencia al dilema ético, religioso o moral que plantea el problema. En su estudio de análisis del tiroteo de Virginia Tech, Schildkraut (2012) propone tres focos de análisis en torno a los cuales puede enmarcarse una noticia relacionada: i) en la denominación y caracterización del suceso, ii) en la forma a través de la cual se representa a la víctima y iii) en la manera 
en la que se refieren al victimario. La convergencia de estos tres elementos puede determinar los tipos de framing que son específicos a esta problemática como tal.

Los enfoques genéricos propuestos por Semetko y Valkenburg (2000) y los enfoques específicos de Schilkraut (2012) pueden adaptarse a este estudio, para identificar cómo estos fueron utilizados en la cobertura inmediata del suceso por parte de The New York Times.

\section{Cobertura mediática de tiroteos masivos en The New York Times}

Uno de los primeros estudios en el ámbito es el de Chyi y McCombs (2004), quienes, a través de su análisis de noticias relacionadas con el tiroteo de Columbine (1999), establecieron un modelo de estudio bifocal que analiza dos variables: tiempo - pasado, presente y futuro- y espacio -individual (centrado en una sola persona), comunitario (pequeños grupos de personas), regional (afectando a un entorno en específico), social (sobre su impacto a nivel social o nacional) o internacional (desde una perspectiva global)-.

Tras aplicar este modelo a Columbine, Chyi y McCombs (2004) afirmaron que el enfoque que primó fue el social y en presente, lo cual puede deberse a la necesidad de que la historia se mantenga novedosa, lo que implica que durante ese mes de cobertura se buscaba reportar el impacto del tiroteo en los sucesos ocurridos posteriormente.

Su modelo sirve de base para investigaciones posteriores como la de Schildkraut y Muschert (2014), quienes aplican este marco de análisis para su estudio comparativo entre la cobertura de los tiroteos de Columbine (1999) y Sandy Hook (2012). Los autores aseguran que la cobertura de los dos eventos dista en cuanto a que en Columbine las historias se centran en los victimarios, los homenajes a las víctimas fatales y el impacto del suceso 
en la comunidad, mientras que, en Sandy Hook, la atención del diario se enfocó en el debate por la regulación y el control de armas.

Schildkraut (2012) realizó un análisis comparativo de la cobertura del tiroteo de Virginia Tech (2007) en The New York Post y The New York Times, enfocado en determinar los temas centrales que dominaron la narrativa del suceso en tres categorías: a) la forma en la que se categorizó el tiroteo; b) la clasificación del victimario, y c) la manera en la que se referían a las víctimas. Si bien existen diferencias en los enfoques de los dos diarios, en los dos casos primó el heroísmo de las víctimas como tema central. Este estudio brinda un marco de referencia para analizar el contenido con un énfasis en el discurso y el uso de lenguaje que puede ser utilizado en esta investigación.

Por último, Schildkraut et ál. (2017) encontraron que, de 90 casos analizados, el 77 \% recibió al menos un artículo en la sección impresa. Sin embargo, el promedio general de noticias dedicadas a cada uno de los tiroteos fue de entre cinco y seis artículos, lo cual implica que, en la mayoría de los casos, este tipo de hechos son considerados noticiosos. Del periodo estudiado, Sandy Hook fue el tiroteo que recibió una mayor cobertura, con 130 artículos relacionados. Así, los autores concluyen que los tiroteos que recibieron mayor atención fueron aquellos que generaron una mayor cantidad de víctimas, una conclusión que comparten Silva y Capellan (2018) en su análisis de 50 años de tiroteos en The New York Times.

Por todo lo anterior, el objetivo general de esta investigación es comparar la cobertura realizada por The New York Times a cuatro tiroteos escolares masivos en Estados Unidos. Para lograrlo, se han planteado tres objetivos específicos: i) analizar los marcos noticiosos utilizados por The New York Times en el cubrimiento de cuatro tiroteos escolares masivos en Estados 
Unidos; ii) caracterizar el contexto político inmediato evidenciado en la cobertura de los cuatro sucesos a través de The New York Times, y iii) identificar patrones recurrentes en la cobertura mediática de los tiroteos escolares masivos.

\section{Metodología}

Esta investigación cuantitativa presenta un análisis de contenido sobre las noticias relacionadas con tiroteos escolares publicadas en el diario The New York Times. Dichos sucesos se seleccionaron con base en tres criterios: i) que el tiroteo hubiese sucedido durante los últimos 25 años; ii) que sucediera dentro de una institución educativa; y iii) que generara un alto saldo de víctimas mortales. Se seleccionaron cuatro casos: Columbine (1999), Virginia Tech (2007), Sandy Hook (2012) y Marjory Stoneman (2018).

Los artículos se seleccionaron a partir de tres criterios: i) que fueran publicados en la edición impresa del diario durante los quince días inmediatamente posteriores al tiroteo; ii) que su tema central girara en torno al suceso, sus consecuencias, la respuesta a este, el porte de armas o los tiroteos masivos en general, y iii) que fueran un producto informativo mayoritariamente escrito, es decir, que consistían en título, lead y contenido textual.

La búsqueda se realizó a través de la base de datos ProQuest y se localizaron un total de 288 textos. Cada artículo se analizó con una matriz de codificación que recogió tanto los elementos contextuales de la noticia, como el análisis de los distintos tipos de frames genéricos, teniendo en cuenta los postulados de Semetko y Valkenburg (2000). Además, se incluyeron dentro de la matriz otras variables como los datos descriptivos de la noticia (extensión, número de página en la que se encuentra y apoyo gráfico). 
Para analizar las noticias de forma más específica, se tomó como base el trabajo de Schildkraut (2012) y los distintos enfoques de análisis aplicados en su estudio comparativo. Posteriormente, el análisis se expandió por medio de un estudio inductivo, que permitió identificar otros elementos relacionados, como la denominación del jefe de Estado, su afiliación política, el partido dominante y el tema con el cual se ha asociado el debate del control de armas. En cuanto a la variable de tipo de historia, se tomó como base el planteamiento de Muschert (2009).

\section{Resultados}

\section{Características formales del corpus}

En total se analizaron 80 noticias sobre el tiroteo de Columbine (1999), 50 de Virginia Tech (2007), 70 de Sandy Hook (2012) y 88 de Marjory Stoneman (2018), para un total de 288 artículos que comprenden la cobertura de los 14 días posteriores a cada uno de los eventos, con el objetivo de analizar el ciclo de vida de los tiroteos.

El tiroteo que recibió una mayor cobertura por parte de The New York Times fue Marjory Stoneman, y el que tuvo menor cobertura fue Virginia Tech. El día posterior a la ocurrencia de los eventos recibió un bajo número de cobertura en comparación con el segundo o el tercer día después del tiroteo. En el caso de Columbine, que tuvo 10 artículos en el día 2, tuvo en este día mayor cobertura y, en el de Virginia Tech, con 10 artículos en el día 3. En el caso de Sandy Hook, el día con mayor cobertura fue el día 4, con 10 noticias, y en el de Marjory Stoneman fue el día 9, que tuvo 12 artículos.

Asimismo, Marjory Stoneman fue el tiroteo con mayor ciclo de vida, pues reportó entre 4 y 6 artículos en los últimos tres días de análisis, a diferencia de los demás tiroteos, que reportaron una menor afluencia de 
artículos en los últimos días. Virginia Tech y Sandy Hook tuvieron un día en el que no se produjo ningún artículo (el día 13 y el día 12, respectivamente) y Columbine tuvo entre 3 y 5 artículos en los últimos tres días de análisis. Estos resultados pueden evidenciarse en la figura 1.

Figura 1. Ciclo de vida noticioso por tiroteo

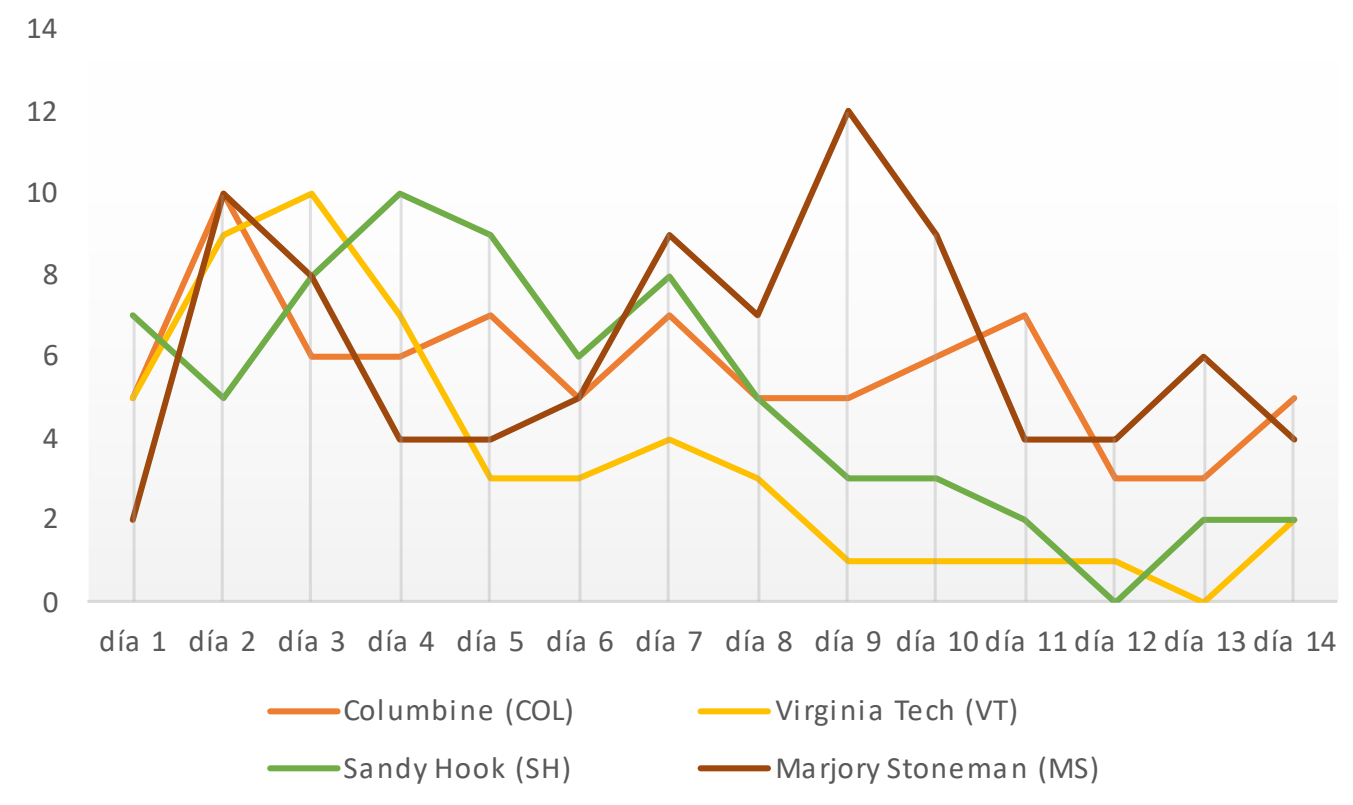

Fuente: elaboración propia.

En total, 37,7\% ( $\mathrm{n}=79)$ del total de artículos aparecieron en la portada del diario. El tiroteo con más artículos en portada fue Marjory Stoneman, con 25, seguido de Sandy Hook, con 22.

Solo un 10,06 \% $(\mathrm{n}=29)$ del total de noticias analizadas aparecieron en la edición dominical de The New York Times y fue Columbine el tiroteo con mayor cobertura esos días, con un total de 10 artículos, y el de menor Virginia Tech, con 3 artículos. Cabe aclarar que, si bien los artículos dominicales disminuyen en cantidad, estos aumentan en extensión. El promedio total de palabras por artículos publicados en domingo fue de 
1314, en contraste con 1090 palabras en promedio de los 288 artículos publicados.

El diario está dividido por secciones demarcadas por letras mayúsculas. En la sección A se encuentra el resumen de noticias, las noticias internacionales, nacionales, artículos de opinión y obituarios. Las secciones B, C, D, E y F varían entre noticias metropolitanas, educación, finanzas, artes, deportes y ciencia. La mayoría de los artículos sobre los tiroteos se encuentran en la sección A, entre las páginas 15 a la 21. Sin embargo, el tiroteo de Marjory Stoneman se caracterizó por localizarse entre las páginas 10 y 20. Por su parte, Columbine y Sandy Hook tuvieron una alta afluencia de artículos localizados entre las páginas 23 y 27 (figura 2).

Figura 2. Distribución de página por tiroteo

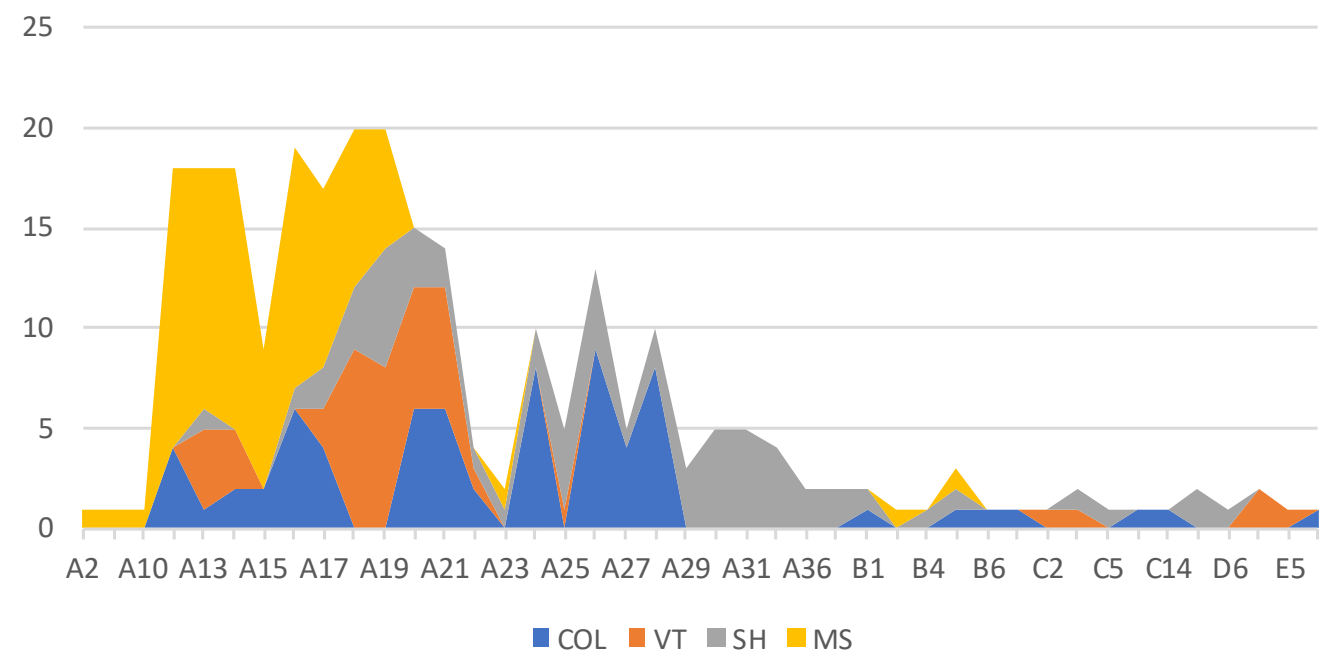

Fuente: elaboración propia.

En la tabla 1 se relaciona el tipo de artículos identificados para propósitos de este estudio: 
Tabla 1. Artículos analizados

\begin{tabular}{|c|c|c|c|c|c|c|}
\hline Tipo de artículo & Noticia & Análisis & Crónica & Perfil & Reportaje & Entrevista \\
\hline $\begin{array}{l}\text { Porcentaje del } \\
\text { total de artículos } \\
\text { analizados }\end{array}$ & $\begin{array}{l}55 \% \\
(n=160)\end{array}$ & $\begin{array}{l}20,1 \% \\
(n=58)\end{array}$ & $\begin{array}{l}8,7 \% \\
(n=25)\end{array}$ & $\begin{array}{l}8,7 \% \\
(n=25)\end{array}$ & $\begin{array}{l}8,3 \% \\
(n=24)\end{array}$ & $\begin{array}{l}0,6 \% \\
(n=2)\end{array}$ \\
\hline
\end{tabular}

Fuente: elaboración propia.

\section{Temas identificados en el contenido}

Como indica la tabla 2, los enfoques de 'consecuencias del suceso' y 'actores involucrados' fueron los más recurrentes:

Tabla 2. Enfoques de los artículos analizados

\begin{tabular}{|l|l|l|l|l|l|}
\hline Enfoques de los artículos & COL & VT & SH & MS & Total \\
\hline Actores & 19 & 18 & 17 & 24 & 78 \\
\hline Acción & 2 & 3 & 4 & 2 & 11 \\
\hline Consecuencias & 27 & 20 & 28 & 40 & 115 \\
\hline Reacciones & 17 & 3 & 9 & 9 & 38 \\
\hline Comentario & 6 & 6 & 3 & 3 & 18 \\
\hline Contexto & 9 & 0 & 9 & 10 & 28 \\
\hline
\end{tabular}

Fuente: elaboración propia.

Asimismo, hallamos que el 32,9\% de los artículos ( $\mathrm{n}=95)$ tienen como tema principal el debate de armas, seguido de todo lo relacionado con el perpetrador del hecho $(\mathrm{n}=37)$ y las víctimas $(\mathrm{n}=35)$, como se ilustra en la figura 3 . 
Figura 3. Distribución de página por tiroteo

\section{Artículos por tema principal}

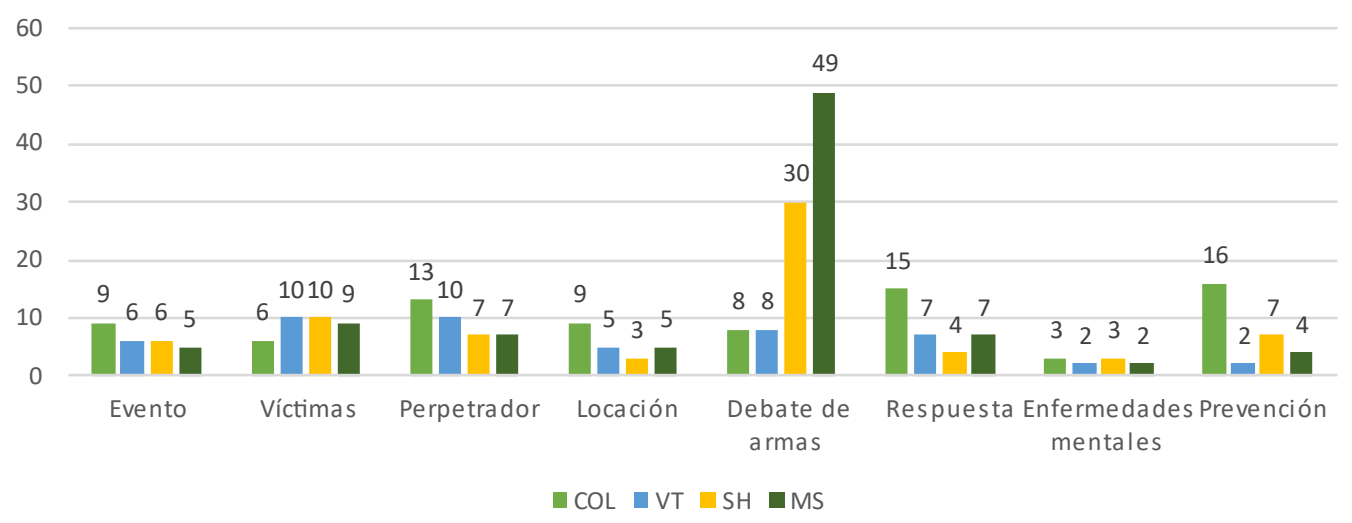

Fuente: elaboración propia.

En cuanto al debate de armas, Marjory Stoneman tuvo la mayor afluencia de artículos (52 \%). Sin embargo, con Sandy Hook se reportó un alza en la cobertura del tema de debate de armas con 30 artículos (32 \%), en contraste con los dos tiroteos previos (Columbine y Virginia Tech), que tuvieron solo un $8 \%$ de sus artículos dedicados al tema.

Se creó una categoría para identificar los casos en los que el debate de armas no es el tema principal, pero es un tema mencionado. En total, 154 artículos de 288 mencionan el control de armas, la mayoría de estos en Marjory Stoneman $(n=71)$, seguido de Sandy Hook $(n=42)$, Columbine $(\mathrm{n}=31) \mathrm{y}$, por último, Virginia Tech $(\mathrm{n}=10)$.

En esta línea, se creó otra categoría que analiza a cuál tema principal se está vinculando el control de armas. Se encontró que buena parte de los artículos vinculan el control de armas al debate político que suscitan los tiroteos, seguido del tema de seguridad, violencia o posesión de armas, y las reacciones en torno a su control, bien sea a través de protestas o voces de apoyo. Estos resultados se pueden ver en detalle en la tabla 3. 
Tabla 3. Tema vinculado al control de armas

\begin{tabular}{|l|l|l|l|l|l|}
\hline \multicolumn{1}{|c|}{$\begin{array}{c}\text { Tema vinculado a control de } \\
\text { armas }\end{array}$} & COL & VT & SH & MS & Total \\
\hline No tiene & 49 & 39 & 28 & 17 & 133 \\
\hline Debate político & 8 & 4 & 14 & 15 & 41 \\
\hline Víctimas & 2 & 1 & 0 & 11 & 14 \\
\hline Evento & 3 & 1 & 2 & 5 & 11 \\
\hline Decisiones sobre armas & 2 & 0 & 5 & 12 & 19 \\
\hline Enfermedades mentales & 3 & 3 & 3 & 5 & 14 \\
\hline Seguridad / violencia / posesión & 10 & 1 & 14 & 11 & 36 \\
\hline $\begin{array}{l}\text { Medidas de respuesta / } \\
\text { reacciones }\end{array}$ & 3 & 1 & 4 & 12 & 20 \\
\hline
\end{tabular}

Fuente: elaboración propia.

\section{Elementos políticos dentro de los artículos}

En cuanto a aspectos políticos, el presidente con mayor número de menciones por artículo fue el republicano Donald Trump, que gobernaba durante el tiroteo de Marjory Stoneman $(n=46)$. En segundo lugar, está el demócrata Barack Obama $(n=26)$. Bill Clinton, el presidente de turno durante el tiroteo de Columbine, fue mencionado en 19 ocasiones y el republicano George Bush solo fue mencionado en 7 artículos sobre Virginia Tech.

Se relacionó el número de artículos que tienen como tema principal el control de armas y se contabilizaron aquellos que hacían mención del presidente de turno (figura 4). En este caso, de los 49 artículos de Marjory Stoneman cuyo tema principal es el control de armas, 31 nombran al presidente Trump y 18 de Sandy Hook mencionaron al presidente Obama. 
Figura 4. Artículos cuyo tema principal es el control de armas por mención del presidente

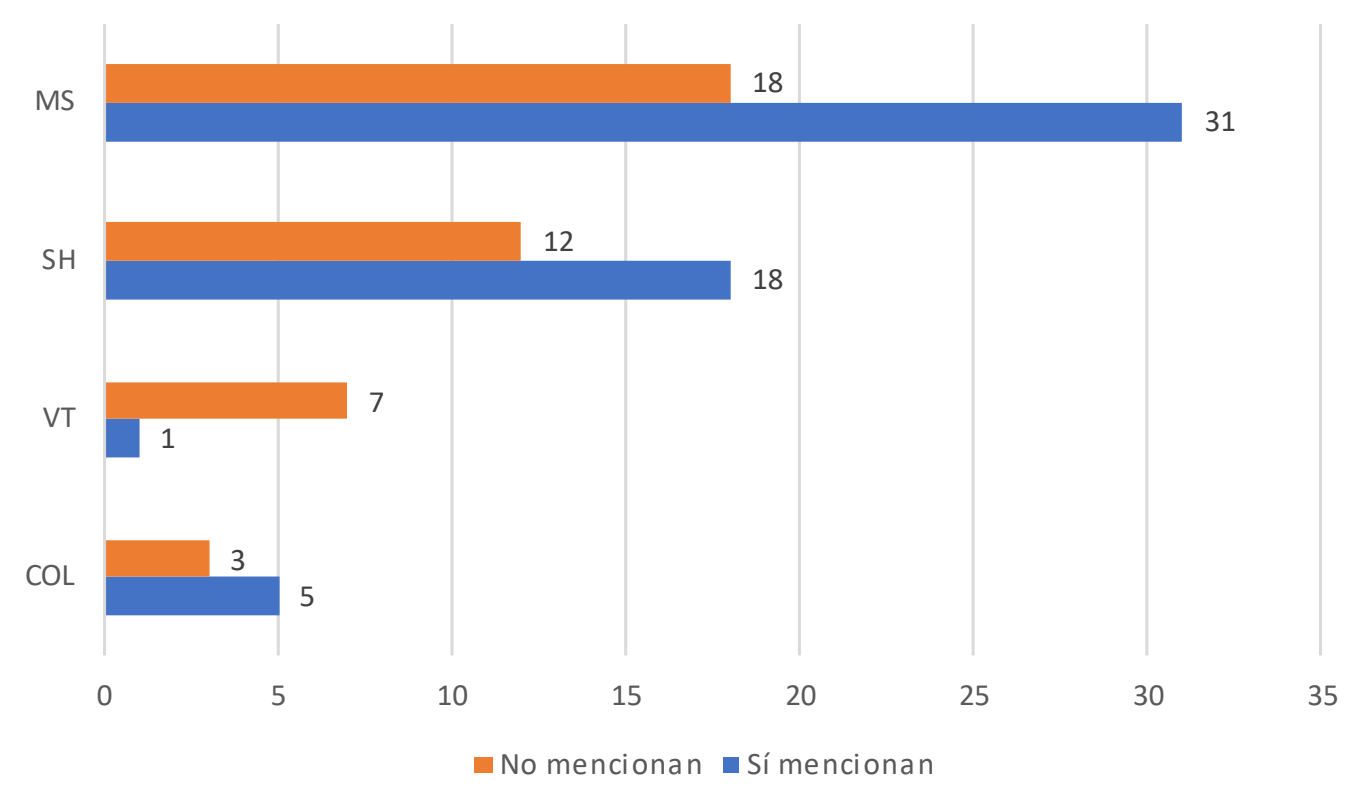

Fuente: elaboración propia.

El tiroteo con mayor mención de los dos partidos políticos principales (demócratas y republicanos) fue Marjory Stoneman, con 28 artículos en los que se menciona a los dos, seguido de Sandy Hook, con 17 menciones en total. El tiroteo con mayor número de menciones exclusivamente a los republicanos fue el de Marjory Stoneman, con 12 artículos.

Asimismo, se analizó la mención a gobiernos anteriores. Barack Obama fue el expresidente con mayor número de menciones $(n=12)$, todas durante la cobertura de Marjory Stoneman, seguido de otro demócrata, Bill Clinton, con seis menciones en tiroteos posteriores a Columbine. George Bush solo se mencionó en tres ocasiones en tiroteos posteriores a Virginia Tech.

De los 288 artículos analizados, 47 mencionan intentos pasados de control de armas. Marjory Stoneman fue el tiroteo con mayor número de menciones, con 23, seguido de Sandy Hook, con 16. Esto representa un 
aumento con relación a los tiroteos anteriores, que en ambos casos hicieron 4 menciones de intentos pasados de regulación.

En total, la Asociación Nacional del Rifle (NRA) es mencionada en 81 artículos, la mayoría de estos en el tiroteo de Marjory Stoneman (47 artículos), un alto número en contraste con Sandy Hook (18 artículos), Columbine (11 artículos) y Virginia Tech ( 5 artículos). El poder político y económico de la NRA, sus acciones y la críticas hacia esta son los principales enfoques de estos artículos, como se puede ver en la tabla 4. Una relación entre la mención de partidos políticos dentro de los artículos que mencionan la NRA arrojó que, en 60 de los 81 artículos que hablan sobre la asociación se menciona al menos uno de los partidos políticos principales. En el $67 \%$ de los casos $(n=40)$ se nombra tanto a demócratas como a republicanos, en el $18 \%(\mathrm{n}=11)$ solo se nombran a los republicanos, que históricamente han estado aliados a esta organización. En $15 \%(n=9)$, solo se alude a los demócratas quienes, en su mayoría, defienden el control de armas.

También se contabilizaron las ocasiones en las que se mencionaba otros tiroteos o eventos violentos previos. La categoría con mayor número de menciones fue la de 'otros tiroteos masivos', que abarca todos aquellos eventos con un tirador activo que no sucedieron dentro de instituciones educativas. Esta categoría es mencionada en 56 de los 288 artículos, seguida de menciones a Sandy Hook, Columbine y otros tiroteos escolares con un menor saldo de víctimas. Otros eventos como los atentados del 9/11 y el tiroteo de la Universidad de Texas, ocurrido en 1966 e incluido por ser el antecedente inmediato al tiroteo de Columbine, también son mencionados, como se muestra en la tabla 5 . 
Tabla 4. Mención de la NRA por tiroteo

\begin{tabular}{|c|c|c|c|c|c|c|}
\hline $\begin{array}{c}\text { Mención de la } \\
\text { NRA }\end{array}$ & $\underset{\text { tiroteo }}{\text { Respuesta al }}$ & $\begin{array}{l}\text { Acciones de } \\
\text { la NRA }\end{array}$ & $\begin{array}{c}\text { Críticas/protestas } \\
\text { a la NRA }\end{array}$ & $\begin{array}{c}\text { Poder } \\
\text { político y } \\
\text { económico } \\
\text { de la NRA }\end{array}$ & $\begin{array}{c}\text { Solo } \\
\text { mencionado }\end{array}$ & $\begin{array}{c}\text { Total artículos por } \\
\text { tiroteo }\end{array}$ \\
\hline Columbine & 2 & 2 & 4 & 3 & o & 11 \\
\hline Virginia Tech & 2 & 1 & $\mathrm{O}$ & 1 & 1 & 5 \\
\hline Sandy Hook & 4 & 4 & 1 & 6 & 3 & 18 \\
\hline Marjory Stoneman & 4 & 8 & 9 & 17 & 9 & 47 \\
\hline Total & 12 & 15 & 14 & 27 & 13 & 81 \\
\hline
\end{tabular}

Fuente: elaboración propia.

Tabla 5. Mención de otros tiroteos o eventos

\begin{tabular}{|c|c|c|c|c|c|c|c|}
\hline $\begin{array}{l}\text { Mención de otros } \\
\text { tiroteos o eventos }\end{array}$ & U. Texas & Columbine & $\begin{array}{l}\text { Virginia } \\
\text { Tech }\end{array}$ & $\begin{array}{l}\text { Sandy } \\
\text { Hook }\end{array}$ & $\begin{array}{c}\text { Otros } \\
\text { tiroteos } \\
\text { escolares }\end{array}$ & $\begin{array}{l}\text { Otros } \\
\text { tiroteos } \\
\text { masivos }\end{array}$ & 11-sep \\
\hline Columbine & 2 & o & $\mathrm{O}$ & O & 14 & 2 & o \\
\hline Virginia Tech & 5 & 12 & $\mathrm{O}$ & $\mathrm{O}$ & 3 & $\mathrm{O}$ & 8 \\
\hline Sandy Hook & 2 & 15 & 13 & $\mathrm{O}$ & 4 & 18 & 5 \\
\hline Marjory Stoneman & $\mathrm{O}$ & 12 & 6 & 41 & 3 & 36 & o \\
\hline Total & 9 & 39 & 19 & 41 & 24 & 56 & 13 \\
\hline
\end{tabular}

Fuente: elaboración propia.

Análisis

ISSN: 0120-8454 | e-ISSN: 2145-9169 | DOI: https://doi.org/10.15332/21459169

Vol. 53 N.o 98 | enero-junio de 2021 


\section{Encuadres}

Debido a que dentro de un artículo pueden existir distintos tipos de frames temporales, se creó una columna para cada uno de ellos, con el fin de verificar si este se aplica o no dentro del artículo. Un conteo de estos evidenció que, en la mayoría de los casos, los artículos están enmarcados en el presente: hacen un seguimiento en tiempo real de la noticia y sus consecuencias inmediatas, con un $51 \%$ de aparición. En el $38 \%$ de los casos, la noticia estaba enmarcada en el pasado, pues hacía referencia a eventos previos. Por último, están los artículos enmarcados en el futuro, con una aparición de tan solo el 11 \% (figura 5).

Figura 6. Framing temporal por total de artículos

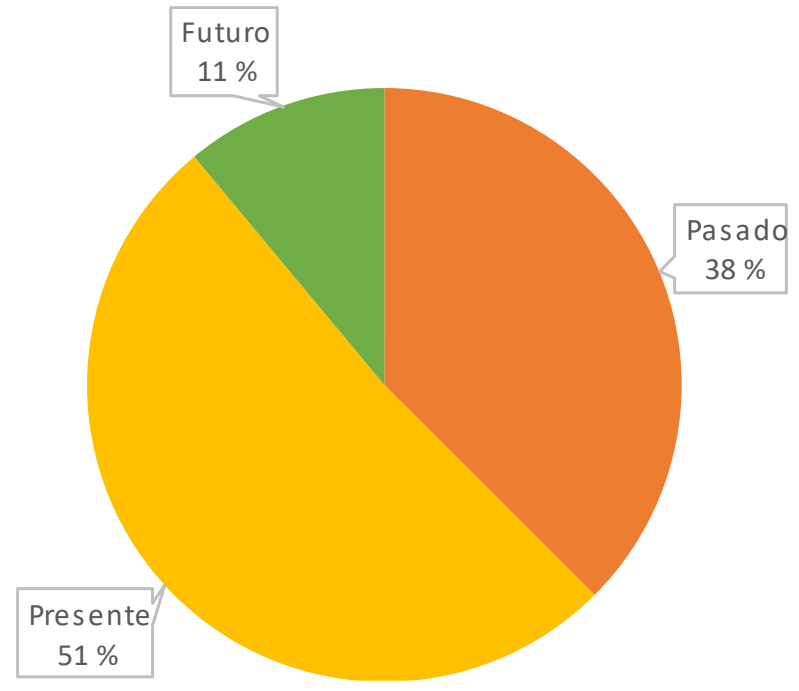

- Pasado

Present

Futuro

Fuente: elaboración propia.

En el framing espacial, la mayoría de los artículos se enmarcan en el plano social (52 \%). En segundo lugar está el plano individual (19\%). Las categorías de 'comunitario' (14 \%) y 'regional' (13\%) comparten un porcentaje similar de artículos. Con un porcentaje mucho menor, se encuentra el marco internacional, con solo un $2 \%$ del total ( 5 artículos). 
Paralelamente, se hizo un análisis del vocabulario utilizado para referirse al evento, al tirador y a las víctimas. El término más común para hablar del tiroteo fue 'tiroteo masivo' (43 \%), seguido por 'masacre' (21 \%) y 'rampage' (que podría traducirse a 'ráfaga de disparos'), con un $9 \%$. En el $7 \%$ de los casos se refieren a estos eventos como "el peor tiroteo" o "uno de los peores de la historia”. Los términos menos utilizados fueron 'carnage' (que significa 'carnicería') (4,8 \%) y ‘bloodbath' (baño de sangre), con un $0,34 \%$.

En cuanto a menciones del tirador, se tuvieron en cuenta referencias a características de su personalidad. El término más utilizado para referirse a los perpetradores de los tiroteos fue el concepto genérico de 'gunman' (tirador) (32\%). La característica más común con la cual se asoció a los perpetradores fue con 'enfermedad mental' o 'personas perturbadas' (10 \% del total). Otras denominaciones recurrentes fueron: 'asesinos' (7,2 \%), 'outcasts'o 'marginados' (4,8 \%), y fríos y calculadores (4,5 \%). La denominación menos usada fue la de 'jóvenes' (1 \%). El 34 \% de los artículos analizados no hacen mención del perpetrador.

Para las víctimas, también se recurrió a un análisis de las características asociadas. El término genérico de 'víctimas' fue el más común (15\%). Otras características recurrentes fueron su determinación (5,5\%), su personalidad $(4,1 \%)$, su heroísmo $(3,1 \%)$ y su juventud $(3,1 \%)$.

El frame más recurrente fue el de 'conflicto' $(\mathrm{n}=181)$, seguido de 'interés humano' ( $\mathrm{n}=180$ ). En este caso se puede evidenciar un aumento en el número de artículos que tienen frame de conflicto, pues los primeros tiroteos tienen una menor recurrencia de este tipo de framing: Columbine, con 39, y Virginia Tech, con 23.

A pesar de que con Sandy Hook se hizo especial énfasis en el tema de control de armas, el número de artículos de frame de conflicto $(n=45)$ 
sigue siendo relativamente bajo en comparación con Marjory Stoneman (74 de los 88 artículos). En contraste, a medida que se avanza en tiroteos y se incrementa el frame de conflicto, se reporta una disminución en el frame de interés humano, siendo Columbine el tiroteo con mayor número de apariciones de este marco (53 de 80 artículos) y Marjory Stoneman, el caso con menor apariciones (en 39 de los 88 artículos).

A estos les sigue el frame de atribución de responsabilidad, que aparece en 148 artículos de 288. De nuevo, Marjory Stoneman es el que reporta una mayor recurrencia de este frame, que, con 64 de 88 artículos, casi duplica la cifra del tiroteo que le sigue en apariciones: Sandy Hook, con 35. A este le sigue Columbine, con 31 artículos y por último, Virginia Tech, con 18. Los frames de moralidad (39 de 288) y de consecuencias económicas (23 de 288) reportan un número mucho menor de recurrencias. El tiroteo con mayor número de artículos que contienen el frame de moralidad es Sandy Hook, con 17 artículos.

\section{Discusión}

\section{Cobertura mediática, tiroteos masivos y política}

Un análisis de los resultados permite entrever que, en los casos analizados, no necesariamente se aplica la idea de que, en tanto exista un mayor número de víctimas, mayor será el valor noticioso de la historia; esto difiere de una de las conclusiones principales de Schildkraut et ál. (2017) y de Silva y Capellán (2018). El tiroteo escolar masivo más mortal hasta el momento ha sido el de Virginia Tech, en 2007, con 33 víctimas mortales; sin embargo, este fue el que tuvo menor número de notas $\mathrm{y}$, simultáneamente, menor ciclo de vida noticioso. Por otro lado, el tiroteo masivo más reciente, el de Marjory Stoneman en 2018, presentó la mayor cantidad de noticias y el mayor ciclo de vida, pues reportó hasta 12 noticias 
en el noveno día de cobertura, algo que no se vio en ninguno de los otros tiroteos.

Se pudo identificar que George Bush, presidente durante el tiroteo de Virginia Tech, no se involucró en el debate de armas y su presencia es mencionada pocas veces en la cobertura ( 7 menciones), la mayoría de estas relacionadas con su respuesta al tiroteo, sin hacer mención del debate de armas. Su falta de involucramiento y de medidas políticas inmediatas en respuesta pueden ser la causa por la cual Virginia Tech tuvo un ciclo de vida tan corto con relación a los demás, en los cuales se vio a un presidente más comprometido -o más obligado a comprometerse- con la causa, lo cual hubiese implicado un mayor desarrollo del evento en el futuro.

Cabe aclarar que, en 2007, año de este tiroteo, habían pasado casi seis años desde los atentados del 9/11, que para ese momento siguen teniendo un fuerte impacto dentro de la opinión pública, como lo demuestran los resultados, y el huracán Katrina había sucedido menos de dos años antes. Así, existen dos precedentes cercanos mucho más devastadores, que de cierta forma hacen que este tiroteo, a pesar de ser el más mortífero, se vea menos grave en contraste con hechos como el 9/11.

En comparación con el republicano George Bush, el demócrata Barack Obama mostró una mayor disposición a adoptar medidas para controlar la posesión de armas; esto, en concordancia con Schildkraut y Muschert (2014), hizo que Sandy Hook se posicionara como el evento coyuntural que implicó un punto de quiebre en torno a la narrativa sobre las armas y el momento en el cual el debate se volvió político. En su cobertura, el diario hace un fuerte énfasis en la respuesta emocional del presidente y recibe sus anuncios por nuevas medidas con optimismo, lo cual se ve reflejado a través del lenguaje utilizado y en el hecho de que la mayoría de la 
cobertura en el tema está mayoritariamente enfocada en el debate de armas.

No obstante, ese debate queda abierto y, para el final de los 15 días de análisis, no se hace seguimiento a su desarrollo, lo que indica que, hasta ese momento, no hubo avance. Sin embargo, el abordaje mediático de este tiroteo muestra a un presidente más comprometido con la causa. Cabe mencionar que esta es la decisión editorial del medio, históricamente reconocido como de tendencia demócrata, lo cual puede tener una clara incidencia en la forma en la que se enmarca el rol del entonces presidente Obama.

Otra variable relevante en este tiroteo es la de las víctimas. La cobertura apela a las emociones a través del uso de adjetivos contundentes con relación a los demás tiroteos, principalmente por las circunstancias en las que sucede: 20 niños de entre 6 y 8 años fueron asesinados, lo que provoca una reacción mucho más visceral por parte del diario. Si bien en los otros tiroteos analizados el principal término utilizado para denominar al suceso es 'tiroteo masivo', en este caso el evento se denomina 'masacre' en la mayoría de las ocasiones, lo cual le da un peso emocional mucho más fuerte. Llama la atención que, a pesar de haber acontecido en lugares con cercanía a Nueva York, los dos tiroteos anteriormente mencionados son los que tienen una menor cobertura.

La lectura de los artículos evidencia que Columbine se convirtió en un hecho noticioso debido, entre otras razones, a su novedad. Al ser el primero en más de treinta años, despierta interés en los medios. Sin embargo, a pesar de su importancia, el debate de armas tiene una relevancia mínima. El enfoque estuvo en los perpetradores.

Bill Clinton, el entonces presidente, es mencionado 19 veces, un número bajo en comparación con Obama y Trump. Sin embargo, el entorno social 
y político de la época puede ser una de las razones por las cuales el debate de armas no cumple un rol central aquí: en 1993, con la ley Brady instaurada por Clinton para el control de armas, se vio una reducción en la ocurrencia de estos acontecimientos, hasta noviembre de 1998 - cinco meses antes de Columbine-, cuando entró en vigor un nuevo sistema de verificación de antecedentes.

En el caso de Marjory Stoneman se puede evidenciar que, a diferencia de los casos anteriores, para la cobertura de este, el evento pasó a ser secundario pocos días después de ocurrido. Aun así, el ciclo de vida del debate político que este tiroteo suscitó lo mantiene vigente dentro de la opinión pública.

Varios aspectos definen el cambio narrativo que posicionó el debate de armas como un tema principal. Si bien este fue un asunto secundario en Columbine y Virginia Tech, el cambio se da con Sandy Hook y se intensifica con Marjory Stoneman. Los marcos ya no se enfocan en las enfermedades mentales como causa principal, sino que se empieza a analizar la implicación del derecho al porte de armas y se ve como un problema sociocultural. Esto implica, a su vez, que actores relacionados con el debate, como el Partido Republicano y la NRA, tomen un rol central en los dos últimos tiroteos.

\section{El rol del medio informativo The New York Times}

En estos casos, el diario juega un papel que podría definirse como de gatekeeper o vigilante: investigaciones relacionadas con el tema se enfocan en el poder político y económico de la NRA y de sus vínculos con el Congreso, en una forma de mantener vivo el debate político. Este enfoque dista de frames asociados con la NRA antes del tiroteo de Sandy Hook, que vinculaban las protestas o las reacciones a la NRA. Así, en este 
caso, el diario toma un rol más participativo como creador de opinión pública, al brindar un periodismo de corte más crítico e investigativo, que da cuenta de cómo evoluciona la narrativa en torno a estos sucesos. Asimismo, una vez se fortalece ese rol de The New York Times como un agente activo dentro del debate de armas, el periódico adquiere un corte más crítico contra el gobierno de turno, específicamente notable en el caso de Donald Trump, cuyas decisiones son cuestionadas o recibidas con incertidumbre. Esto podría relacionarse a su vez con la confrontación abierta en contra de los medios que planteó el presidente Trump durante su campaña, siendo este diario uno de sus principales objetivos.

Lo anterior, al mismo tiempo, está relacionado con el protagonismo que adquieren las víctimas de los tiroteos en la cobertura de los mencionados sucesos, inversamente proporcional con la cobertura de los victimarios. Una vez se les da relevancia a sus testimonios, sus críticas también se elevan, y así la cobertura de Sandy Hook evidenció una fuerte crítica hacia el presidente Trump y el Partido Republicano a través de las voces de los afectados. Sin embargo, esta decisión de framing por parte del medio deja ver su clara intencionalidad y, por qué no, parcialidad en torno al tema.

Este aspecto es un aporte central del presente estudio y define su intención de transformación social: identifica un cambio respecto a la forma en la que se presentan las historias, pero sobre todo en la relevancia que se le brinda a un tema sobre otro y se establecen las bases para identificar cambios en las narrativas futuras. Es importante resaltar que se identifica un proceso de transición que responde al contexto social, político e histórico en el cual cada uno de estos eventos está enmarcado: estos cuatro tiroteos no son vistos como eventos aislados, sino como acontecimientos que se generan dentro de un contexto cambiante, el cual tiene repercusiones en la cobertura mediática que se hace de ellos. Se ha 
identificado una narrativa que, en cada caso, depende del contexto en el cual se desarrollan los eventos.

Este estudio permite identificar que, si bien esas voces de rechazo, los reclamos y las exigencias de cambio van haciéndose notar a medida que se avanza la línea del tiempo del análisis, estas se convierten en un actor central de la cobertura mediática que, a medida que adquieren importancia, hacen disminuir el rol de los victimarios.

Comprender esta transición implica interpretar cómo los medios responden al periodo en el cual se sitúa el acontecimiento. En línea con su posición ideológica, The New York Times adquiere una visión mucho más crítica que se hace notable, especialmente en el último tiroteo, lo cual aporta una perspectiva respecto a la forma en la que se aborda la cobertura mediática: el medio se convierte, también, en un actor del debate y, a juzgar por las publicaciones que se realizan, el medio es consciente de ello. Esto permite identificar el medio como un motor de transformación social (dependiendo de la orilla política desde donde se observe) que, si bien se encarga de ser un transmisor de información, también incita a la acción.

\section{Algunas precisiones sobre los marcos analizados}

El 'presente' es el frame predominante en los cuatro casos, en concordancia con el análisis de Columbine, de Chyi y McCombs (2004), y de Sandy Hook, de Schildkraut y Muschert (2012). Dicho frame toma relevancia a medida que avanza el ciclo de vida de la noticia, puesto que se hace un seguimiento en tiempo real de las consecuencias del suceso. El frame en 'futuro' tiene una recurrencia mucho menor, en la medida que se relaciona con las posibilidades o predicciones del debate político que se va a desarrollar o de posibles medidas futuras en torno al suceso. 
Durante los primeros días, el framing espacial de las noticias tiende a enmarcarse en el plano individual y se enfoca bien sea en la experiencia de la víctima o en la motivación del victimario. No obstante, a medida que avanza el ciclo de vida, los artículos toman un cariz más enfocado hacia los planos comunitario o social, posiblemente para enfocarse en las consecuencias del evento y no del evento como tal, como una forma de mantener el ciclo de vida de la historia y así continuar captando la atención del público.

En todo este contexto, el debate por la posesión de armas se interpreta como una problemática lejana y ajena a los ciudadanos, casi que fuera del alcance de estos. Esto se relaciona con el concepto de "pánico moral" acuñado por Rocque (2012). Tal sensación, reforzada por una percepción de inseguridad que convierte a este tipo de actos en sucesos de tipo terrorista, se evidencia con mayor claridad en los primeros tres casos y con una mucha menor recurrencia en el caso de Marjory Stoneman. The New York Times hace énfasis en estos temas de una forma dicotómica: si bien en algunos casos se culpa a la sociedad por la tragedia, en otros es ella una víctima más del perpetrador.

Como se mencionó, tanto en el caso del tiroteo como en el del tirador y de las víctimas, las denominaciones genéricas son las predominantes, lo cual puede deberse a la intención del medio de mantenerse como un agente objetivo. El uso de palabras que implican una mayor carga emocional como 'masacre', 'carnicería' o ‘baño de sangre' tienden a ser mucho menos comunes, pero conllevan una función más estratégica. Cuando se usan, cumplen con la función de fortalecer el imaginario generado en torno a estos sucesos como escenarios del drama y la tragedia colectiva, y tienen un alto contenido simbólico, que convierte al asesinato masivo en un espectáculo público (Warnick et ál., 2010), un punto de convergencia entre lo informativo y lo performativo (Sumiala y Muschert, 2012). 
El frame principal de los tiroteos también da cuenta de la transición narrativa que pasa a convertirlo de un evento que genera alerta y terror a un evento que es visto como una oportunidad política: en Columbine y Virginia Tech, el frame de interés humano prima sobre los demás, mientras que en Marjory Stoneman, el frame más recurrente es el de conflicto. En el caso de Sandy Hook, por su parte, estos dos frames aparecen el mismo número de veces, lo cual da cuenta de esa necesidad de establecer un balance entre las emociones que genera la muerte de estos menores y la necesidad de una acción política.

El marco de atribución de responsabilidad, por su parte, está estrechamente ligado al frame de conflicto (en 119 de los casos aparecen juntos, en contraste con 72 ocasiones en donde el marco de atribución de responsabilidad aparece junto al marco de interés humano) y, en la mayoría de los casos, se atribuye la responsabilidad al Estado o sus organismos. Consecuentemente, el debate político generará una atribución de responsabilidad bien sea desde la voz de los actores implicados o por decisión editorial del medio. En contraste con el frame de moralidad, esto permite evidenciar que el debate no es de tipo moral, a pesar de que estén vidas en juego. Es decir, no se cuestiona con respecto a si el porte de armas es algo inherentemente bueno o malo, ni existe una mención que indique que el acto cometido por los perpetradores está justificado de ninguna manera.

Así, un análisis de la relación de frames permite evidenciar que la forma en la cual se enmarca la noticia está relacionada con el rol que tiene el tiroteo. En la mayoría de los casos en los cuales el frame es de interés humano, el tiroteo es visto como el fin en sí mismo, mientras que, cuando el frame es de conflicto, el tiroteo es visto como el medio para un fin, que, en la mayoría de los casos, tiene implicaciones políticas o económicas. 


\section{Palabras finales}

Este análisis plantea un aporte a la transformación social en cuanto a la inclusión de variables de tipo político, lo cual permite analizar los tiroteos masivos ocurridos en las últimas décadas en los Estados Unidos desde una nueva perspectiva, pero a su vez demuestra la importancia de analizar los eventos trágicos en el marco sociocultural y político en el cual se desarrollan. A través de este estudio se identificó que, a medida que el debate de armas adquirió un mayor rol dentro de la sociedad estadounidense, los principales actores vinculados - partidos políticos, gobierno de turno y la NRA - fueron adquiriendo una importancia gradual, que a su vez está ligada con la postura de los mandatarios dentro del debate. El rol de los presidentes no solo añade nuevos temas de análisis para la cobertura de eventos trágicos, sino que también permite abrir nuevos caminos para analizar, comprender y estudiar el rol que cumplen los medios y sus decisiones editoriales, para construir la opinión pública en torno a un tema determinado.

En el estudio se encontraron algunas limitaciones provenientes de los enfoques escogidos, como fue el caso de la falta de preguntas para clasificar artículos de tipo cultural. En este caso, temas como la violencia en el cine y en los videojuegos toman una fuerte relevancia, pero pocas preguntas eran aplicables. Futuros estudios podrían determinar nuevos parámetros para aproximarse a ese lado del debate con mayor profundidad.

\section{Referencias}

Almasy, S. (2018, 25 de marzo). March for Our Lives: Top moments that made up a movement. CNN. https://edition.cnn.com/2018/03/24/us/march-for-our-liveswrap/index.html 
Altheide, D. (2009). The columbine shootings and the discourse of fear. American Behavioral Scientist, 52(10), 1354-1370.

https://doi.org/10.1177/00027642093325.52

Birkland, T. y Lawrence, R. (2009). Media framing and policy change after Columbine. American Behavioral Scientist, 52(10), 1405-1425. https://doi.org/10.1177/0002764209332555

Chyi, H. y McCombs, M. (2004). Media Salience and the Process of Framing: Coverage of the Columbine School Shootings. Journalism and Mass Communication Quarterly, 81(1), 22-35. https://doi.org/10.1177/107769900408100103

Cook, P. y Goss, K. (2014). The Gun Debate. Oxford University Press.

Duwe, G. (2000). Body count journalism: the presentation of mass murder in the news media. Homicide Studies, 4(4), 364-399.

https://doi.org/10.1177/1088767900004004004

Entman, R. (1992). Framing: toward clarification of a fractured paradigm. Journal of Communication, 43(4) 51-58. https://doi.org/10.1111/j.1460-2466.1993.tb01304.x

Fausset, R., Kovaleski, S. y Mezzei, P. (2018, 16 de febrero). On a day like any other at a Florida school, 6 minutes of death and chaos. The New York Times. https://www.nytimes.com/2018/02/16/us/stoneman-douglas-shooting.html

Hawdon, J., Oksanen, A., Räsänen, P. y Ryan, J. (2012). School shootings and local communities: an international comparison between the United States and Finland. University of Turku.

Kocsis, M. (2015). Gun ownership and gun culture in the United States of America. Essays in Philosophy, 16(2), 154-179. https://doi.org/10.7710/1526-0569.1530

Krotz, F. y Hepp, A. (2013). A concretization of mediatization: How 'mediatization works' and why mediatized worlds are a helpful concept for empirical mediatization research. European Journal for the Philosophy of Communication, 3(2), 119-134. https://doi.org/10.1386/ejpc.3.2.137 1

Larkin, R. (2007). Comprehending Columbine. Temple University Press.

Luca, M., Malhotra, D. y Poliquin, C. (2020). The impact of mass shootings on gun policy. Journal of Public Economics, 181. https://doi.org/10.1016/j.jpubeco.2019.104083

Análisis

ISSN: 0120-8454 | e-ISSN: 2145-9169 | DOI: https://doi.org/10.15332/21459169

Vol. 53 N.0 98 | enero-junio de 2021 
Muschert, G. (2007). Research in School Shootings. Social Compass, 1(1), 60-80. https://doi.org/10.1111/j.1751-9020.2007.00008.x

Muschert, G. (2009). Frame-changing in the media coverage of a school shooting: The rise of Columbine as a national concern. The Social Science Journal, 46(1), 164170. https://doi.org/10.1016/j.soscij.2008.12.014

Newman, B. y Hartman, T. (2017). Mass shootings and public support for gun control. British Journal of Political Science, 49(4), 1527-1553. https://doi.org/10.1017/So007123417000333

Newman, K. y Fox, C. (2009). Repeat tragedy rampage shootings in American high school and college settings, 2002-2008. American Behavioral Scientist, 52(9), 1286-1308. https://doi.org/10.1177/0002764209332546

Drake, B. (2013, 17 de septiembre). mass shootings rivet national attention but are a small share of gun violence. Pew Research Center. http://www.pewresearch.org/facttank/2013/09/17/mass-shootings-rivet-national-attention-but-are-a-small-shareof-gun-violence/

Reich, G. y Barth, J. (2017). Planting in fertile soil: The National Rifle Association and State Firearms Legislation. Social Science Quarterly, 98, 485-499.

https://doi.org/10.1111/ssqu.12423

Rocque, M. (2012). Exploring school rampage shootings: Research, theory, and policy. The Social Science Journal, 49(3), 304-313. https://doi.org/10.1016/j.soscij.2011.11.001

Savage, C. (2018, 18 de diciembre). Trump Administration Imposes Ban on Bump Stocks. The New York Times. https://www.nytimes.com/2018/12/18/us/politics/trumpbump-stocks-ban.html

Schildkraut, J. (2012). Media and massacre: a comparative analysis of the reporting of the 2007 Virginia Tech shootings. Fast Capitalism, 9(1). https://www.uta.edu/huma/agger/fastcapitalism/9 1/schildkrautg 1.html

Schildkraut, J., Elsass, J. y Meredith, K. (2017). Mass shootings and the media: Why all events are not created equal. Journal of Crime and Justice, 223-243. https://doi.org/10.1080/0735648X.2017.1284689 
Schildkraut, J. y Hernández, T. (2014). Laws that bit the bullet: A review of legislative responses to school shootings. American Journal of Criminal Justice, 39(2), 358374 .

Schildkraut, J. y Muschert, G. (2014). Media salience and the framing of mass murder in schools: a comparison of the Columbine and Sandy Hook Massacres. Homicide Studies, 18(1), 23-43. https://doi.org/10.1177/1088767913511458

Schultz, J., Muschert, G., Dingwall, A. y Cohen, A. (2013). The Sandy Hook Elementary School shooting as tipping point: "This time is different". Disaster Health, 1(2), 65-73. https://doi.org/10.4161/dish.27113

Semetko, H. y Valkenburg, P. (2000). Framing European politics: a content analysis of press and television news. Journal of Communication, 5O(2), 93-109. https://doi.org/10.1111/j.1460-2466.2000.tbo2843.x

Silva, J. y Capellan, J. (2018). The media's coverage of mass public shootings in America: fifty years of newsworthiness. International Journal of Comparative and Applied Criminal Justice, 43(1), 77-97. https://doi.org/10.1080/01924036.2018.1437458

Simon, R. (2004, 10 de septiembre). Assault weapons ban ends quietly. Los Angeles Times. https://www.latimes.com/archives/la-xpm-2004-sep-10-na-guns10story.html

Shultz, J., Muschert, G., Dingwall, A. y Cohen, A. (2013). The Sandy Hook Elementary School shooting as tipping point. Disaster Health, 1(2), 65-73. https://doi.org/10.4161/dish.27113

Sumiala, J. y Muschert, G. (Eds.). (2012). School shootings: mediatized violence in a global age. Emerald Group Publishing Limited.

Waldman, M. (2015). The Second Amendment: A biography. Simon \& Schuster.

Warnick, B., Johnson, B. y Rocha, S. (2010). Tragedy and the meaning of school shootings. Educational Theory, 6o(3), 371-39o. https://doi.org/10.1111/j.1741$5446.2010 .00364 \cdot \mathrm{x}$ 